\title{
Conditions for creating a balance between learning styles on the example of the material of the discipline "Ecological Chemistry and Environmental Monitoring"
}

\author{
Mariia Kolchanova ${ }^{1}$, Tetiana Derkach $^{2}$, and Tetiana Starova ${ }^{1, *}$ \\ ${ }^{1}$ Kryvyi Rih State Pedagogical University, Department of Chemistry and Methods of its Teaching, Kryvyi Rih, 50086, Ukraine \\ ${ }^{2}$ Kyiv National University of Technologies and Design, Department of Professional Education in Technologies and Design, Kyiv, 01011, \\ Ukraine
}

\begin{abstract}
Aspects of learning styles modelled on R. Felder and B. Soloman are discussed in detail. The results of the study of the educational advantages of students of Kryvyi Rih State Pedagogical University of the speciality "014 Secondary education (Chemistry)" are presented. It is shown that the majority of students in the group are those who study visually, sensitively, actively and consistently. According to studied features of the student's groups didactic material on the theme "Ecological Chemistry of the Lithosphere" of the content module "Ecological Chemistry of Environmental Objects" was elaborated and its role and place in the structure of the educational process determined. Forms of work that involve the use of different cognitive functions are described and therefore contribute to their balanced development. It allows a person to be flexible in the unrestrained development of technological progress, to be open to different ways of obtaining information and perceiving it without resistance and stress.
\end{abstract}

\section{Introduction}

Introducing a student-centred model of higher education requires taking into account the subject's preferences regarding the methods of study [1,2].

According to this approach, one should first understand the preferred learning style of the whole group of students, as well as learning preferences of individual students $[3,4]$.

It is essential and topical to introduce an individualcentric model in the training of future specialists, who will eventually take the place of a teacher in the studentteacher system [5]. Such an approach will allow students to use their available cognitive functions and improve their gnostic functions and, as a result, to develop in a rapid rhythm of human progress.

The aim of the study was to study the prevailing learning styles of groups of students majoring in chemistry with the subsequent use of acquired knowledge to optimise teaching methods in the process of studying ecological chemistry.

\section{Methods}

The work was performed at Kryvyi Rih State Pedagogical University. Students of the Faculty of Natural Science participated in the survey to identify the preferred learning styles of all involved students.

Totally 63 persons are first- to fifth-year students; they take undergraduate or graduate courses in the speciality "Chemistry". Senior students studied the integrated course "Ecological Chemistry and Environmental Monitoring". This course fruitfully links theoretical knowledge of chemistry and their practical application.

The instrument, known as Index of Learning Style and developed by R. Felder and B. Soloman (thereinafter Felder-Soloman's model) was used [6, 7]. All respondents were interviewed to respond to 44 questions, which allow one to estimate available preferences in four complementary dimensions.

The instrument categorises individuals in line with their preferences in perception - sensing (Sns in clipped form) or intuitive (Int), information input - visual (Vis) or verbal (Vrb), data processing - active (Act) or reflective (Ref) and understanding of information sequential (Seq) or global (Glo).

In other words, each of four dimension consists of two opposite styles or a pair of a style and anti-style. They are scored by an 11-point scale. The advantage of one of two opposite styles is estimated on the base of distribution of 11 points between them.

In this paper, the results related to preferred learning styles will be given as percentages indicating the relative number of students in the sample with a particular style. Therefore, the number of students will always be $100 \%$ for a given style and anti-style pair.

Consider in detail aspects of learning styles of the R. Felder and B. Soloman model, namely the main characteristics of cognitive functions, if one of the styles

* Corresponding author: simaneneko@ukr.net 
prevails.

\subsection{Sensing and intuitive types of learning}

Sensing-type students prefer to learn the facts. They should solve problems using known methods. They do not like difficulties and surprises. So, they will be upset if they receive a question on educational material that has not been covered in detail in a lecture room. Sensing students are also attentive to detail, well-remembered, and do laboratory works, more practical and careful.

Intuitive students prefer theories and hypotheses, love innovation, and do not like repetition. They have a better understanding of new concepts and tend to feel more confident with abstractions and formulas. They work faster and more inventive [7].

Students with a pronounced sensing learning style do not like courses that are not relevant to reality. Intuitive students do not like instructional courses that require a lot of memorisation and monotonous calculations.

The benefits of one or the other way of learning can be strong, medium or weak. Students should be able to act in both ways to be effective in teaching and solving problems. If they favour intuition too much, they may lose important details and make mistakes in calculations and lab work due to inattention. If they rely solely on sensing learning, they will be able to reduce learning to cramming and repetition of known methods, refusing to live experiment and develop creative thinking [7].

Sensory-type students remember and understand information better when they see how it relates to real life. When they study a discipline that contains much of the material in the form of theories and abstractions, difficulties may arise. The teacher should be given specific examples for each concept and methodology and show how these concepts are used in practice to prevent obstacles in learning theoretical problems. If the teacher does not provide sufficient specific data, sensing students should find it on their own or in a textbook, or other texts, or using a joint brainstorming session with their learning colleagues [6].

Usually, intuitive type students take most lectures without problems. However, if such students find themselves in classes where they are primarily required to memorise and mechanically use formulas, they may have problems and boredom. Therefore, the teacher should be provided with interpretations and theories related to the facts studied. If this does not happen, students of intuitive type should try to find regular connections on their own [7].

\subsection{Visual and verbal types of learning}

Students who have a distinct visual learning style are better remembered for what they see - pictures, diagrams, flowcharts, graphs, movies and visual demonstrations. Verbal students are more likely to receive information in the form of words - written and oral explanations. Both types absorb more when the information is presented both visually and verbally [7].

Most classes use very little visual information: students mainly listen to lectures and read materials written on blackboard and textbooks, as well as manipulative materials. The facts indicate that most students are people with a visual type of perception. In other words, this means that they do not get as much as they could if the visual presentation of data were used more in the class [6].

If the student has a visual type of perception, he/she must independently find diagrams, sketches, diagrams, photographs, graphs, or any other visual representation of course materials, which is predominantly verbal. References to videos, videos of the course will be useful. It is the best for students to use maps or flowcharts where critical points of a theme are depicted in the middle of squares or other figures, with demonstrations of connections between concepts (in the form of a line with arrows between blocks) [6]. For students of the visual type, it is useful to use colour markings of records when each colour has its meaning - for example, highlighting concepts related to the same topic, class, type, etc. [7].

Students of verbal type should write short summaries or translations, of course, materials in their own words. Group work can be beneficial to them. They understand the material better by listening to the explanations of classmates and learn even more when explaining the content to others [6].

\subsection{Active and reflective types of learning}

Students who have the advantage of an active learning style are better able to understand and acquire new knowledge by doing something with them. Reflective students should first calmly reflect on the information received and only then begin to work with it [6].

The advantage of one type or another may be strong, moderate or weak. It is desired to have a balance of both. If the student always does, and then thinks, at first, he or she may take up the case too hastily, which will create problems. If he spends too much time thinking, he can never do anything about it.

As a rule, active students are more comfortable working in a group, as opposed to reflective students who prefer to study alone. Attending lectures without any movement and physical activity, apart from giving notes, is not easy for both types, but especially tricky for active students [7].

If there is little classroom time when discussing discipline or discussing it together, students with an active type of perception should make up for that. To do this, they need to prepare for a class together with a group of friends to take turns explaining topics to each other. It is useful for them to imagine that they can be asked to the next control and to represent how they will respond [6].

When students have a little time in the lecture room to reflect on new knowledge, persons with a reflexive type of perception should try to make up for the lack of that. To do this, they need not only read and memorise the educational material but also stop from time to time to repeat what they have read and think about possible questions and apply the knowledge they have learned. It is also helpful for them to write small summaries based 
on what they have read or taken notes in the audience, presenting the material in their own words. Such an approach requires additional time but will allow better study of information [7].

\subsection{Consistent and global types of learning}

Students with a predominant sequential learning style gain understanding through successive steps, each of which is a logical continuation of the previous one. Global-type students tend to learn big leaps, gathering information almost haphazardly, and then suddenly grasping the essence [7].

Students with consistent perceptions tend to follow a logical step-by-step search. Students with global perceptions can solve problems quickly and put the pieces together once they have understood the big picture [6].

Many people may mistakenly qualify as "global" because everyone felt astonished by the "illumination" [7]. However, what makes the perception global or consistent happens before the outbreak. Students with a very pronounced global perception who cannot think sequentially may experience severe difficulties until they understand the overall picture [6]. Even when received, they may have a vague idea of the details of the subject. At the same time, consistent students may know a great deal about specific aspects of the subject under study but not understand how they relate to its other components or other matters [7].

Most courses in higher education are taught sequentially. However, if the student has a consistent type of perception, and the teacher moves from one topic to another and misses the logical steps, it may be difficult for the student to keep track of his or her reflections and remember something. One needs to complete the missing steps with the help of the teacher's answers or yourself, referring to the directories. Students should logically arrange the lecture material. To develop global thinking, one must try to relate each new topic to one that has been studied before. The more a student does this, the deeper will be the understanding of the problem [6].

If a student has a global type of learning style, then it will be useful for them to understand their need for a general picture of the subject under study before mastering the details. If a teacher starts a new topic without trying to explain how it relates to what has been learned before, it can cause problems. However, there are steps a student can take to get a total picture faster [7].

Before beginning, the first paragraph of the next section of the text, a student who has a global type of learning style needs to review the section completely to understand a general idea. Initially, this will take extra time, but will subsequently avoid multiple revisions of individual parts [7]. Instead of spending time reviewing each subject for a short time each day, it may be more useful for such students to study topics in large blocks [6]. Students of this type should try to relate the subject under study to what they already know: to ask the teacher to help them see the links or find them in the additional literature on their own. When a student suddenly understands new material and understands how it is related to other topics and disciplines, he/she will be able to apply his/her new knowledge in a way that most consistent students do not dream of [7].

\section{Results and discussion}

\subsection{Conflict of styles}

Lecturers have their advantages of learning styles [8, 9]. Most lecture courses are aimed at a small number of people who can perceive and process information intuitively, verbally, reflectively and consistently. Such a situation creates a disadvantage for many students.

Lab work, being inherently sensing, visual, and active, could offset some of the imbalance. However, most laboratory work involves, first and foremost, mechanical exercises. They illustrate only a small part of the concepts discussed at the lectures and rarely provide a significant understanding or development of skills. Thus, sensing, visual, active and global students rarely meet their educational needs when studying at higher education institutions.

The discrepancy between teaching style and teaching style has several serious implications. In this case, the students feel as if the communication is taking place in an unknown foreign language.

These problems can be minimised, and the quality of education can be significantly improved if teachers take into account the particularities of student preferences in teaching styles $[10,11]$.

It is challenging to create the conditions for the presentation of information in a form that satisfies all possible styles of student learning in one audience. There are different approaches to solving this problem.

The works we have done earlier describe the methodology of choosing methods, forms and teaching aids, taking into account the peculiarities of learning styles of students of different specialities [12, 13, 14]. He has a right to life and another approach that involves applying the techniques of presenting information conveniently to each style for a while.

The development of all cognitive styles is beneficial for students. Therefore, seeking to strike a balance for everyone in the learning process can be helpful. Then students will have natural learning activities available to them, as well as creating conditions for the development of other learning styles. Such a situation can promote active learning and a positive attitude towards it, as well as lead to the development of less developed abilities [15].

When working on the development of a global teaching style, it is better to study the material with the means of visual techniques that are chosen in such a way that students can offer a generalised conclusion from their analysis. To do this, you should first show the schematics of the links of the elements for study, experiments, results, and then allow students to reach the provisions of specific theories independently.

When developing a reflective teaching style, teachers 
sometimes need to stop during the lecture to give time to think and formulate questions. You should also schedule small group problem-solving sessions in which group students spend one or several minutes solving any of the many different issues and problems.

For example, such questions as: "Start solving this problem," "What is wrong with what I wrote on the board?" have produced incorrect results: how many possible explanations can you come up with? ".

Also, to develop a global teaching style, it is necessary to demonstrate the logical connection of particular topics, to show the interaction between current material and other topics of the same discipline, other courses and daily life.

Encouraging or engaging in self-help in homework is essential. Students who participate in collective learning, both in and out of the classroom, receive better grades and show greater enthusiasm [15].

\subsection{Found preferences in learning styles}

Let us consider in detail the results obtained in the study of the learning preferences of all interviewed students (Fig. 1).

A significant difference was observed in three dimensions: Sensing (Sns) (65.7\%) / Intuitive (Int) (34.3\%); Visual (Vis) (64.2\%) / Verbal (Vrb) (33.2\%) and Active (Act) (59.5\%) / Reflective (Ref) (40.5\%).At the same time, no essential difference was found in the fourth dimension of Sequential (Seq) $(50.1 \%) /$ Global (Glo) $(49.9 \%)$.

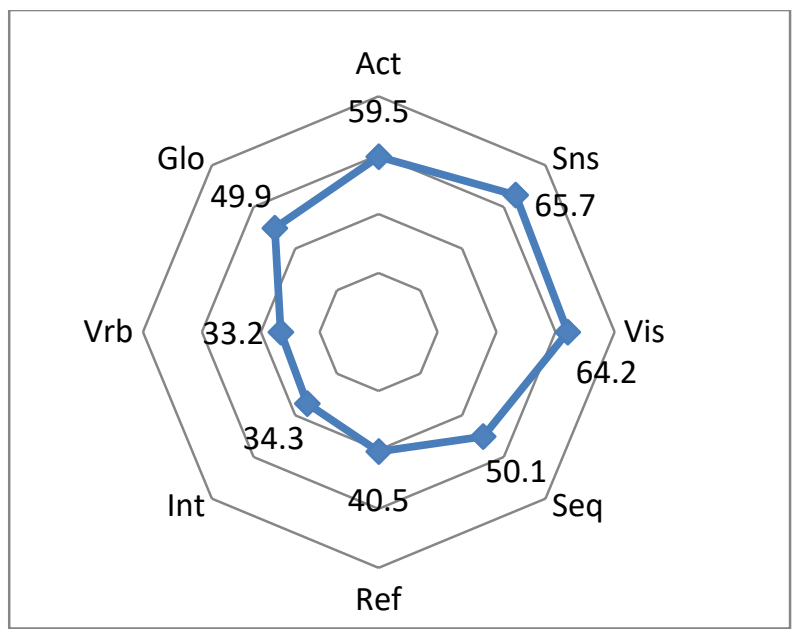

Fig. 1. Preferences in learning styles for students of the Faculty of Natural Sciences of KSPU, the speciality 014 Secondary education (Chemistry).

In other words, style prevails over anti-style in three dimensions. In the fourth dimension, there is a balance between style and anti-style.

Typically, learning style is a relatively stable and weakly variable characteristic of a person, which is formed under the influence of its psychological and physiological characteristics. For example, it was shown in [16] that it is weakly dependent on the year of study for first- to fourth-year undergraduate students.

The opposite view is that dominant learning styles can change under the influence of external circumstances. Such influencing factors may include the field of study and type of material being studied, delivery mode, the age of an individual, his motivation and educational level, etc.

It is also commonly believed that learning styles are not sensing to the student's gender, but may vary significantly between groups of students in different fields of study.

Thus, the question of the stability of learning styles and their dependence on students' gender and age can still be considered debatable. The results obtained in the paper allow us to evaluate the influence of the above factors.

For this reason, the results of testing the learning styles of all students were divided into groups by gender (Fig. 2 and 3).

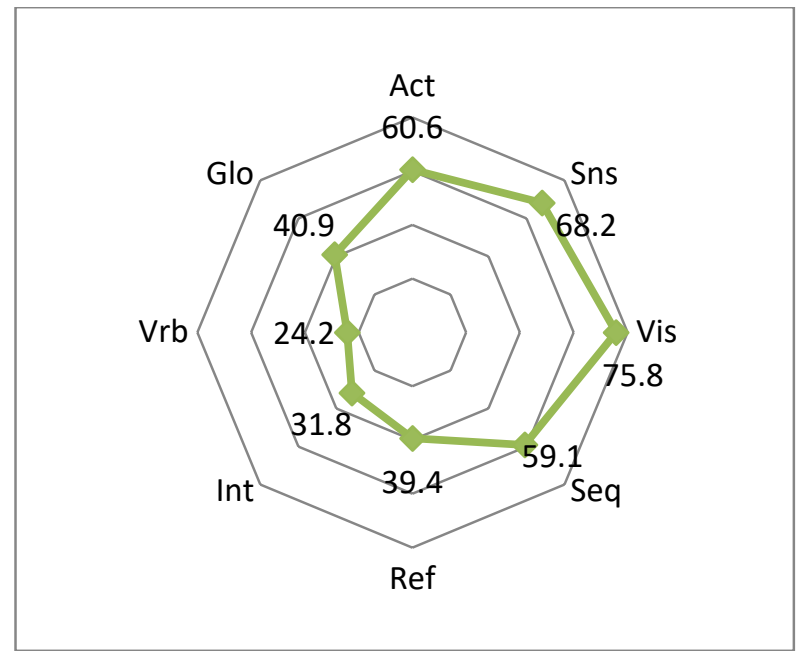

Fig. 2. Preferences in learning styles for male students.

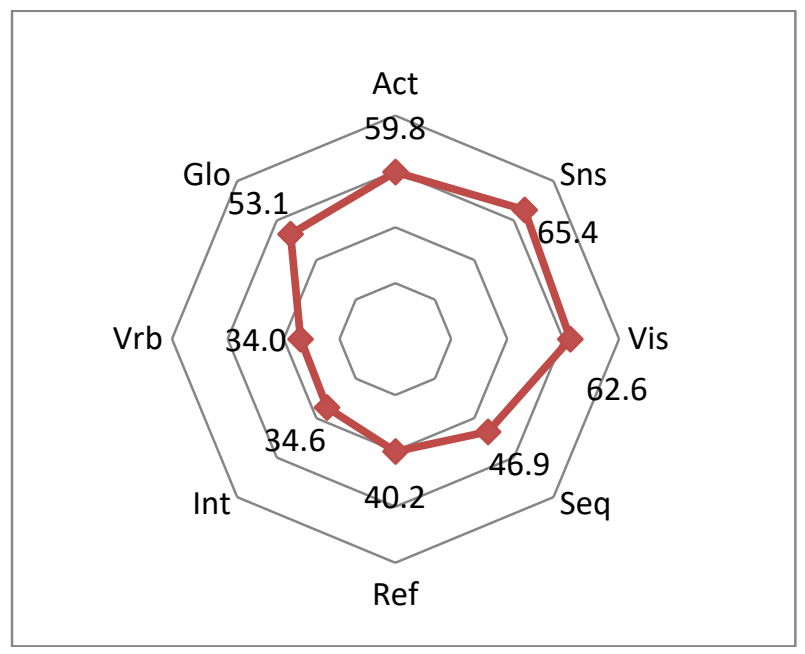

Fig. 3. Preferences in learning styles for female students.

Comparing the results of the two study groups "boys" and "girls", we can see that respondents-boys and respondents-girls have a difference between the two dimensions: "boys" - Vis (75.8\%) / Vrb (24.2\%), Seq $(59.1 \%)$ / Glo (40.9\%); "girls" - Vis (62.6\%) / Vrb $(34.0 \%)$ Seq $(46.9 \%) /$ Glo $(53.1 \%)$.

In two other characteristics, the difference is almost not noticeable: "boys" - Sns (68.2\%) / Int (31.8\%), Act 
(60.6\%) / Ref (39.4\%); "girls" - Sns (65.4\%) / Int (34.6\%) and Act (59.8\%) / Ref (40.2\%).

Also, the results of testing the learning styles of all students were divided into groups by age (Fig. 4, 5).

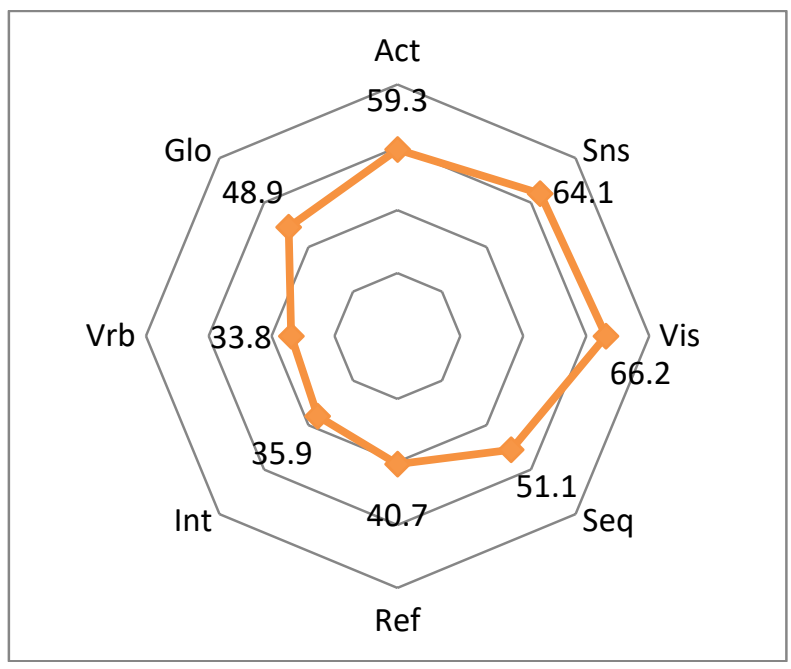

Fig. 4. Preferences in learning styles for students of $17-$ 20 years old.

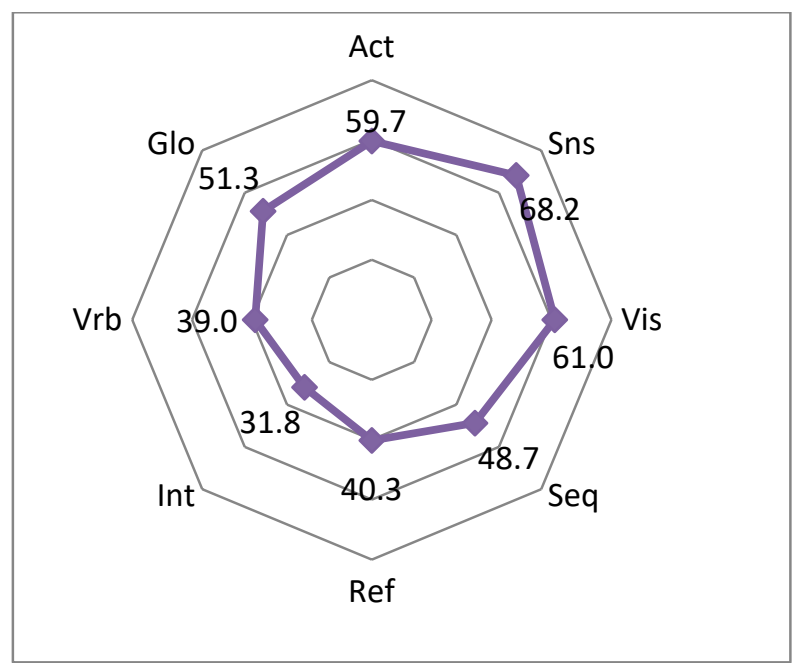

Fig. 5. Preferences in learning styles for students of $21+$ years old.

Comparing the results of the two study groups for ages of 17-20 and 20+ years, we concluded that the respondents in these groups had only minor differences.

For 17-20 years, the preferred styles are as follows: Sns $(64.1 \%)$ / Int (35.9\%), Vis (66.2\%) / Vrb (33.8\%), Act (59.3\%) / Ref (40.7\%), Seq (51.1\%) / Glo (48.9\%).

For $21+$ years, Sns $(68.2 \%) /$ Int $(31.8 \%)$, Vis $(61.0 \%) / \operatorname{Vrb}(39.0 \%)$, Act $(59.7 \%) / \operatorname{Ref}(40.3 \%)$, Seq $(48.7 \%)$ / Glo (51.3\%).

In our opinion, there is a slight difference in the respondents' learning styles because all the respondents' study in the same speciality.

\subsection{Optimisation of teaching methods to study ecological chemistry}

Taking into account the obtained profiles of educational advantages in groups, we have prepared a didactic material on the topic "Ecological chemistry of the lithosphere" of the content module "Ecological chemistry of environmental objects". The role and its place in the structure of the educational process are determined. Most students in the group are those who study visually, sensitively, actively, and consistently. That is why we used in the lecture the methods, forms and teaching resources that are well percept by them.

Example:

- a large amount of multimedia presentation data was used for visual perception of information during the lecture;

- for the of sensing data processing, lecture information was provided based on life stories and situations;

- to attract an active component of the training types, several problematic situations on this topic were created. Students worked in small groups for several minutes over their decision;

- a link between current material and everyday life was demonstrated for the consistent component.

For the lecture information on the following processes was elaborated: soil formation, weathering and its varieties, leaching, gouging, salting and others, as well as learning about the participation of living organisms in soil formation.

Submission of material on fundamental processes in the lithosphere was also adapted to the prevailing stylistic characteristics of students, namely: visual, sensing, active and consistent, but other techniques have already been used. Example:

- a multimedia presentation with various diagrams and photographs illustrating the content of the theme was used for visual stylistic characteristics during the class;

- for the sensing style, the information of the lecture was related to the environment, which is directly an integral part of human life;

- for the active component, lectures specifically made mistakes in the content and provided an opportunity for students in small groups (2-3 people) to consider where the inaccuracy was made;

- for a consistent component, the connection between current material and everyday life was demonstrated.

During the laboratory session, we formed practical knowledge about the composition of the soil and some of its indicators. For this purpose, the following methods were applied:

- illustrations of the mechanical composition of the soil, video of bean growth, and instructions for planting it in the soil were used simultaneously with the parallel text that described these processes to learn by visual style during the laboratory work;

- for the sensing style, the information related to the fertile surface layer of the lithosphere, which is directly connected with human life, was provided. Students were asked to find signs that determine the quality of the soil and its use in human activity;

- an analysis of soils in which beans grew was used for the active style of the students in the laboratory. Students worked in small groups analysing soils.

The content of students' independent work included tasks that, in our opinion, are intended to help develop a 
global, reflective, verbal, intuitive styles of learning activity.

Here are examples of the tasks of students' independent work. To develop a global characteristic of the Seq/Glo pair of learning styles, students were invited to do the following: "Use the guides, the Internet, and other recommended sources to learn about the content of the Ecological Chemistry of the Lithosphere. Determine the importance of chemical processes in soils for the formation of biogeochemical cycles of chemical elements and their substances in the nature of our planet".

To satisfy of the reflective style of learning of the Act/Ref aspect, we asked students to do the following: "Using lecture notes, read the study material, occasionally pausing to repeat what you have read. Write small abstracts based on what you have read. What is the main source of pollution of the lithosphere? Describe the main components of the emissions from such a source and the effects of their influence on the chemical composition of the fertile soil layer. What are some ways we can deal with the primary and re-contamination of key areas?"

To satisfy the requirements a verbal style in the Vis/Verb pair, we asked students to do the following task: "Using the above text, make a diagram of the biogeochemical cycle of Carbon.

Carbon in nature:

The chain of carbon atoms is the basis of all organic matter: proteins, fats, carbohydrates and other compounds that are necessary for the life of all living organisms.

The Carboniferous circulation between wild and inanimate nature occurs at high speed. The main inorganic compounds of Carbon are its oxides $\left(\mathrm{CO}_{2}\right.$ and $\mathrm{CO}$ ), as well as carbonate that makes up carbonate rocks.

The most mobile Carbon compound in the atmosphere, which plays a significant role in the cycle, is carbon dioxide $\left(\mathrm{CO}_{2}\right)$.

Carbon's central reserve is concentrated in Carboniferous rocks (carbonates, dolomite, etc.) at the bottom of the ocean and in the Earth's crust, as well as fossil fuels. Carbon reserve in the atmosphere is much smaller. However, it plays a significant role in the cycle due to its mobility.

As a result of the relatively small reserves in the atmosphere, the Carbon cycle is more vulnerable than the Nitrogen cycle.

Recently, the carbon dioxide content in the atmosphere has been steadily increasing, indicating that the equilibrium processes in the biosphere are disturbed. The reason for this is human economic activity: high carbon dioxide emissions from burning fossil fuels, reducing forest area, pollution of the oceans, and therefore decreasing photosynthesis intensity - carbon dioxide binding. Increasing carbon dioxide content is the main cause of the greenhouse effect and an increase in the average temperature on the planet".

For the development of intuitive style in the subsystem Sns/Int, we proposed students to do the following task: Tailings form a large amount of dust under the influence of wind flows, which leads to the pollution of atmospheric air and its deposition in large areas of land. Suggest a plan for minimising dust generation.

Thereby in the course of the study, we started to introduce students to different forms of work that involve using the different cognitive functions, and therefore contribute to the development of their balance. The latter, in turn, allows a person to be flexible in the unrestrained development of technological progress, to be open to different ways of receiving information and perceiving it without resistance and tension.

Students, as a whole, evaluated the completed tasks at a high level, which indicates that the students' perception of new tasks is positively fulfilled, without sabotage.

\section{Conclusions}

So, in the course of the study, we started to introduce students to different forms of work that involve different cognitive functions, and therefore contribute to the development of their balance. The latter, in turn, allows a person to be flexible in the unrestrained development of technological progress, to be open to different ways of receiving information and perceiving it without resistance and tension.

\section{The prospects for future research}

Preliminary diagnosis of students' styles in the group allows the teacher to create conditions for enriching students' stylistic behaviour, which will increase the productivity of their intellectual actions.

The use of the educational resources that are created in this work will help to prevent the occurrence of "conflict of learning styles" of teachers and students during classes.

The findings of the paper can be used in the educational process at higher education institutions to teach the disciplines of the pedagogical cycle. For example, "Methods of teaching chemistry in a specialised school and vocational education institutions", as well as professional disciplines "Organic chemistry", "Computer statistical processing results" and others.

Continuing experiments to establish links between students' academic performance and the development of their cognitive styles is a promising area of research. Summarising of their results will help to formulate principles for the organisation of efficient training of future chemical specialists.

\section{References}

1. F. Coffield, D. Moseley, E. Hall, K. Ecclestone, Learning Styles and Pedagogy in post-16 learning: a systematic and critical review (Learning and Skills Research Centre, London, 2004), p. 182

2. C. Damsa, T. de Lange, Uniped 42, 9 (2019). doi:10.18261/issn.1893-8981-2019-01-02 
3. A.M. Alzain, S. Clark, G. Ireson, A. Jwaid, International Journal of Emerging Technologies in Learning 13(9), $41 \quad$ (2018). doi:10.3991/ijet.v13i09.8554

4. A.M. Alzain, G. Ireson, S. Clark, A. Jwaid, in 2016 World Congress on Sustainable Technologies (WCST), (Piscataway, London, 12-14 December 2016), pp. 109-114

5. C. Tulbure, Procedia - Social and Behavioral Sciences $33, \quad 398 \quad$ (2012). doi:10.1016/j.sbspro.2012.01.151

6. R.M. Felder, R. Brent, Teaching and Learning STEM: A Practical Guide (Jossey-Bass, San Francisco 2016), p. 336

7. R.M. Felder, Index of learning styles (ILS), https://www.webtools.ncsu.edu/learningstyles. Accessed 13 Feb 2020

8. S. Rahimi, Y. Sohrabi, A. H. Nafez, M. Dabirian, Indian Journal of Public Health Research \& Development 8(2), 386 (2017). doi:10.5958/09765506.2017.00146.2

9. J. Fu, Int. J. Educ. Dev. Using Inf. Commun. Technol. 9, 112 (2013)

10. J.T. E. Richardson, Learning and Individual Differences 288 21, 2011 ). doi:10.1016/j.lindif.2010.11.015

11. A.L. Franzoni, S. Assar, Journal of International Forum of Educational Technology and Society 12(4), 15 (2009)

12. T.M. Derkach, T.V. Starova, Science and Education, 6, 51 (2017). doi:10.24195/2414-4665-2017-6-8

13. B. Williams, T. Brown, Curr. Pharm. Teach. Learn. 5, 110 (2013). doi:10.1016/j.cptl.2012.09.003

14. Y.H. Chang, Y.Y. Chen, N.S. Chen, Y.T. Lu, R.J. Fang, Eurasia J. Math. Sci. Technol. Educ. 12(5), 1273 (2016). doi:10.12973/eurasia.2016.1512a

15. R. M. Felder, Reaching the second tier: Learning and teaching styles in college science education, (1993), https://www.engr.ncsu.edu/wpcontent/uploads/drive/1g7mzNhke6ErAkNXsQlyxB smkaR-m8oe-/1993-Secondtier.pdf. Accessed 13 Feb 2020 